\title{
The prevalence and features of the polycystic ovary syndrome in young South Indian women from Pondicherry
}

\author{
Willis G. Sheelaa*, Rekha Radha
}

Department of Obstetrics \& Gynecology, Sri Manakula Vinayagar Medical College and Hospital, Puducherry-605107, India

Received: 10 March 2014

Accepted: 23 March 2014

\section{*Correspondence:}

Dr. Willis G. Sheelaa,

E-mail: drgwilissheelaa@gmail.com

C 2014 Sheelaa WG et al. This is an open-access article distributed under the terms of the Creative Commons Attribution Non-Commercial License, which permits unrestricted non-commercial use, distribution, and reproduction in any medium, provided the original work is properly cited.

\begin{abstract}
Background: Aim of current study was to correlate clinical presentation of menstrual irregularity with ultrasound ovarian morphology and assess prevalence of occult PCO.

Methods: Fifty women in the age group of 15-25 years attending gynaecology OPD with the complaints of menstrual irregularity were selected for the study. Fifty women within the same age group without any of these complaints were enrolled as control.

Results: Past In study group $80 \%$ were obese, 50\% had acne, 26\% had hirsutism, $94 \%$ had oligomenorrhea, $80 \%$ had ovarian morphological changes and $6 \%$ had amenorrhea. In the control group $48 \%$ were obese and $46 \%$ had ovarian changes.

Conclusions: Occult PCOD category need follow up and laboratory assays, as they have risk of PCOD and long term implications like diabetes, hypertension, dyslipidemia and cardiovascular disease.
\end{abstract}

Keywords: Prevalence, Occult PCO, PCOS

\section{INTRODUCTION}

Poly Cystic Ovarian Disease (PCOD) is a heterogeneous multisystem endocrinological disorder of reproductive age. PCOS set early in adolescent life, but clinically manifest in reproductive age with long term implications of diabetes hypertension, dyslipidemia, cardiovascular disease which forms syndrome $X$. This syndrome is a combination of clinical, biochemical and ultrasound parameters of ovarian morphology. The quoted incidence is $8-10 \%$ by various authors.

Androgen Excess Society defines PCOS as a syndrome of ovarian dysfunction with three cardinal features namely hyperandrogenism, anovulation and Polycystic ovary morphology with Rotterdam criteria. PCOS cause anovulation and infertility in $20 \%$, insulin resistance and hyperinsulinemia in 50-70\% and obesity in $60 \%$ young women.

\section{Aim}

To correlate clinical findings with ultrasound ovarian morphology and assess prevalence of occult PCO

\section{METHODS}

Fifty young women in the age group of 15-25 years attending Gynae OPD of Sri Manakula Vinayagar medical college \& hospital, Puducherry, S. India with the complaints of menstrual irregularity were included in the study. Fifty women with complaints of acne and hirsutism attending dermatology OPD of SMVMCH were enrolled as controls. Height, weight and BP were recorded; BMI calculated History regarding infertility, amenorrhea, and menstrual irregularities were taken using a questionnaire. Study subjects and controls were subjected to ultra-sonogram to study ovarian morphology. PCOD was diagnosed using Rotterdam 
criteria of 12 or more small follicles seen in ovary giving the appearance of "String of Pearls", each follicle of 2-9 $\mathrm{mm}$ diameter, ovaries volume $>10 \mathrm{~cm}^{3}$. Clinical presentation was correlated with ultra sonographic ovarian morphology.

\section{RESULTS}

The obesity was correlated with body mass index (BMI). Among study subjects $80 \%$ were obese while in the control group $48 \%$ were found to be obese. Assessment of Acne and hirsutism ( $\mathrm{n}=100)$ showed that $50 \%$ had acne in the study group, and $30 \%$ in control group had acne. It was also found that incidence of acne is less in women with BMI $<19(8 \%)$ and incidence of hirsutism is more in women with BMI $>26$. In the study group, out of 25 women with acne, 13 had hirsutism also, 12 women did not have either acne or hirsutism.

In the control group, Out of 15 women who had acne, only 7 had hirsutism, 28 did not have either acne or hirsutism. Incidence of hirsutism is more in study group.

Table 1: Interrelations between BMI, obesity, acne, hirsutism and menstrual patterns among study subjects.

\begin{tabular}{|c|c|c|c|c|c|c|}
\hline \multirow{2}{*}{ BMI } & \multirow{2}{*}{ Obesity } & \multirow{2}{*}{ Acne } & \multirow{2}{*}{ Hirsutism } & \multicolumn{3}{|c|}{ Menstrual patterns } \\
\hline & & & & Regular & Oligomenorrhea & Amenorrhea \\
\hline$<19$ & $10(20 \%)$ & $5(10 \%)$ & Nil & 7 & 4 & Nil \\
\hline $20-25$ & $20(40 \%)$ & $11(22 \%)$ & $4(8 \%)$ & 4 & 13 & 1 \\
\hline$>26$ & $20(40 \%)$ & $9(18 \%)$ & $11(22 \%)$ & 2 & 17 & 2 \\
\hline
\end{tabular}

Table 2: Interrelations between BMI, obesity, acne hirusutism and menstrual patterns among controls.

\begin{tabular}{|lllllll|}
\hline \multirow{2}{*}{ BMI } & Obesity & \multirow{2}{*}{ Acne } & Hirsutism & \multicolumn{2}{l|}{ Menstrual patterns } \\
\cline { 5 - 7 } & & & Regular & Oligomenorrhea & Amenorrhea \\
\hline$<19$ & $26(52 \%)$ & $3(6 \%)$ & nil & 20 & 1 & Nil \\
\hline$>26$ & $7(14 \%)$ & $5(10 \%)$ & $2(4 \%)$ & 9 & 6 & Nil \\
\hline
\end{tabular}

Oligomenorrhea is the commonest menstrual irregularity seen in our study. In the study group $94 \%$ had oligomenorrhea and $6 \%$ had amenorrhea. The occult PCO category comprises of 10 subjects in the study group and 23 subjects in the control group. The occult PCO comprised of subjects whose ultra-sonogram did not show any morphological changes in the ovary. Women with typical PCOS type of ovarian dysfunction without hyperandrogenism are termed as dysregulated ${ }^{6}$ PCO. In our study, 12 women in study group, and 23 in controls did not have acne or hirsutism.

Table 3: Ultra sonogram findings among study subjects and controls.

\begin{tabular}{|lllll|}
\hline \multirow{2}{*}{ BMI } & Cases & & \multicolumn{2}{c|}{ Controls } \\
& PCO & Occult PCO & PCO & Occult PCO \\
\hline$<19$ & 2 & Nil & Nil & Nil \\
\hline $20-25$ & 13 & Nil & 19 & 23 \\
\hline$>26$ & 25 & 10 & 8 & Nil \\
\hline Total & 40 & 10 & 27 & 23 \\
\hline
\end{tabular}

\section{DISCUSSION}

Prevalence of PCOS in our study was $8 \%$ which corresponds with other studies conducted by various authors. Azziz $\mathrm{R}^{1}$ from USA has reported an incidence of
$8 \%$ in black and $4.8 \%$ in white women. Asuncion ${ }^{2}$ has reported $6.5 \%$ PCOS in unselected population in Spain. From a community sample from Australia,

March $\mathrm{WA}^{3}$ has reported $8.7 \%$ of PCO. Richards ${ }^{4}$ has reported an incidence of $28 \% \mathrm{PCO}$ in obese women and $5.5 \%$ in lean women from Madrid. The prevalence of polycystic ovarian syndrome ranged from $4.8-8.7 \%$. 80 study subjects were obese with BMI $>20$. $48 \%$ were obese in the control group. Richards ${ }^{4}$ has reported $28 \%$ of his study subjects with PCOS were obese. Georgina Jones ${ }^{5}$ from U. K. in her cross sectional study with South Asian and Caucasian women has quoted an incidence of obesity of $42.3 \%$ in South Asian women with PCOS and $38.6 \%$ obesity in white Caucasian women. In women with BMI less than $19,8 \%$ had acne. Asuncion $\mathrm{M}^{2}$ has reported $12.3 \%$ of his PCOS women had acne. Out of 25 women with acne in study group, 13 had hirsutism. In control group, out of 15 women who had acne, 7 had hirsutism. Interrelation between BMI, obesity, acne hirsutism and menstrual patterns among study subjects, and controls is shown in Table $1 \& 2$. Women with typical PCOS type of ovarian dysfunction without hyper androgenism are termed as dysregulated PCO. ${ }^{6}$ In our study, 12 women in study group, and 23 in controls did not have acne or hirsutism. In study subjects, $68 \%$ women had oligomenorrhea and 3 had amenorrhea. In the control group $30 \%$ had oligomenorrhea and $70 \%$ had 
regular cycle. Georgina Jones ${ }^{5}$ has reported that $35.3 \%$ of South Asian women and $38.6 \%$ white Caucasian women presented with obesity, infertility and menstrual irregularity. Oligomenorrhea was seen in $42.3 \%$ SouthAsian women and $35.4 \%$ in white Caucasian women in her series. PCOS was diagnosed as per Rotterdam Criteria. Ultra sonogram findings among study subjects and controls are shown in Table 3. 10 out of 50 women who presented as PCOS in study group and 23 out of 50 controls did not show any changes in ovarian morphology. These women fall into a category of Occult PCO (OPCOS). Mortenson ${ }^{6}$ from USA has reported $25 \%$ of asymptomatic volunteers with PCOS, did not show any change in ovarian morphology in his study. These young women with occult PCOS and dysregulated PCO may develop established syndrome in reproductive age with long term sequel such as diabetes, hypertension and infertility. They need regular follow up.

\section{CONCLUSIONS}

Young women who are diagnosed as dysregulated PCO are at a high risk to develop PCOD and long term sequel such as diabetes, hypertension and infertility. So they need follow up, additional diagnostic parameters for diagnosis and management. This a preliminary study. Assays are needed in addition to ultra-sonogram for the further evaluation.

\section{ACKNOWLEDGEMENTS}

The authors would like to thank Dr. Sivagami who did ultra-sonogram on the study subjects and controls.

Funding: No funding sources Conflict of interest: None declared

Ethical approval: The study was approved by the institutional ethics committee

\section{REFERENCES}

1. Azziz R, Woods KS, Reyna R, Key TJ, Knochenbauer ES, Yilde ZBO. The prevalence and features of the polycystic ovary syndrome in an unselected population. J Clin Endocrinol Metab. 2004;89(6):2745-9.

2. Asuncion M, Calvo RM, San Millan JL, Sancho J, Avila S, Escobar-Morialle HF. A prospective study of the prevalence of polycystic ovary syndrome in unselected Caucasian women from Spain. J Clin Endocrinol Metab. 2000;85(7):2434-8.

3. Mark WA, Moore VM, Willson KJ, Phillips DI. The prevalence of polycystic ovary syndrome in a community sample assessed under contrasting diagnostic criteria. Hum Reprod. 2010;25(2):544-51.

4. Lero RS, Alvarez-Bosco F, Botella-Cametero JI, San Millan JL, Escobar-Morialle HF. Prevalence and characteristics of polycystic ovary syndrome in overweight and obese women. And Intern Med. 2006;166:2081-6.

5. Jones Gl, Palep Singh M, Ledger WL, Balen AH, Jenkinson C, Campbell MJ, Lashen H. Do south Asian women with PCOS have poorer health related quality of life than Caucasian women with PCOS? A comparative cross sectional study. Health Qual life Outcomes. 2010;20(8):149.

6. Mortensen M, Etormann DA, Little John E, Rosenfield RL. Asymptomatic volunteer with a polycystic ovary are a functionally distinct but heterogeneous population. J Clin Endocrinol Metab. 2009;94(5):1579-86.

DOI: $10.5455 / 2320-1770 . i j \operatorname{cog} 20140611$

Cite this article as: Sheelaa WG, Radha R. The prevalence and features of the polycystic ovary syndrome in young South Indian women from Pondicherry. Int J Reprod Contracept Obstet Gynecol 2014;3:344-6. 